result in measurable but modest changes in $\mathrm{N}$ concentration over short distances in some streams, whereas much larger changes are associated with disturbance of the adjacent landscape by humans.

25. J. D. Newbold, J. W. Elwood, M. S. Schulze, R. W. Stark, J. C. Barmeir, Freshwater Biol. 13, 193 (1983).

26. P. J. Mulholland et al., Verh. Internat. Verein. Limnol., in press.

27. W. K. Dodds et al., Ecosystems, in press.

28. S. K. Hamilton et al., Biogeochemistry, in press.

29. J. L. Tank et al., Limnol. Oceanogr. 45, 1013 (2000).
30. W. M. Wollheim et al., Limnol. Oceanogr. 46, 1 (2001) 31. J. R. Webster, B. C. Patten, Ecol. Monogr. 49, 51 (1979)

32. J. D. Newbold, J. W. Elwood, R. V. O'Neill, W. Van Winkle, Can. J. Fish. Aquat. Sci. 38, 860 (1981).

33. S. P. Seitzinger, C. Kroeze, Global Biogeochem. Cycles 12, 93 (1998).

34. J. L. Meyer, J. B. Wallace, in Ecology: Achievement and Challenge, M. C. Press, N. Huntly, S. Levin, Eds. (Blackwell Science, Oxford, 2001), pp. 295-317.

35. F. J. Triska, A. P. Jackman, J. H. Duff, R. J. Avanzino, Biogeochemistry 26, 67 (1994).
36. This work is supported by NSF grants DEB-9628860, DEB-9810222, and OPP-9615949. More than 100 students and scientists gathered the information for this synthesis paper. We especially thank S. Johnson, L. Ashkenas, N. Grimm, S. Fisher, C. Dahm, K. Renzanka, J. Merriam, S. Findlay, C. Fellows, R. Hall, R. Holmes, C. Rensha, D. Sanzone, K. MacNeale, and E. Bernhardt for fieldwork, laboratory analyses, and discussion. K. Tholke performed all isotopic analyses.

25 October 2000; accepted 1 March 2001

\title{
Tropical Origins for Recent North Atlantic Climate Change
}

\author{
Martin P. Hoerling, ${ }^{1}$ James W. Hurrell, ${ }^{2}$ Taiyi $\mathbf{X u}^{1}$
}

\begin{abstract}
Evidence is presented that North Atlantic climate change since 1950 is linked to a progressive warming of tropical sea surface temperatures, especially over the Indian and Pacific Oceans. The ocean changes alter the pattern and magnitude of tropical rainfall and atmospheric heating, the atmospheric response to which includes the spatial structure of the North Atlantic Oscillation (NAO). The slow, tropical ocean warming has thus forced a commensurate trend toward one extreme phase of the NAO during the past half-century.
\end{abstract}

Large changes in the climate of the extratropical North Atlantic have occurred since 1950. Decadal variations, superimposed on a trend, are especially evident in the leading spatial structure of variability in atmospheric pressure (Fig. 1), known as the NAO. The trend toward its positive phase is described by a strengthening of the middle latitude westerly flow with anomalously low (high) pressure over the subpolar (subtropical) North Atlantic from the surface into the stratosphere $(1,2)$. This change in atmospheric circulation has contributed substantially to the observed surface warming of the Northern Hemisphere $(\mathrm{NH})$ in recent decades (1$3)$, coherent large-scale changes in precipitation over Europe and the Middle East $(1,2)$, and important changes in both terrestrial and marine ecosystems $(4,5)$. Yet in spite of these large impacts, the physical mechanisms that govern these decadal and longer term atmospheric variations are poorly understood. We present evidence that concomitant changes in rainfall and atmospheric heating, associated with the progressive warming of the equatorial oceans, have played a central role in producing the observed climate changes over the North Atlantic.

It is well established that much of the atmospheric circulation variability in the form of the NAO arises from processes inter-

${ }^{1}$ Climate Diagnostics Center, National Oceanic and Atmospheric Administration-Environmental Research Laboratories, Boulder, CO 80303, USA. ${ }^{2}$ National Center for Atmospheric Research, Post Office Box 3000 Boulder, CO 80307, USA.

To whom correspondence should be addressed. Email: mph@cdc.noaa.gov nal to the atmosphere. For instance, the observed spatial pattern and amplitude of the NAO (Fig. 1) are typically well simulated in atmospheric general circulation models (AGCMs) forced with fixed climatological annual cycles of solar insolation and sea surface temperature (SST), as well as fixed atmospheric trace gas composition $(6,7)$. Such variability exhibits little temporal coherence, and it has been argued that the observed NAO time series cannot be easily distinguished from a random stationary process $(8)$. A possible exception to this interpretation is the strong trend toward the positive index polarity of the NAO over the past 50 years (Fig. 1). Multi-century climate simulations with fixed climatological forcing, for example, do not reproduce North Atlantic interdecadal changes that compare in magnitude to those recently observed (9). One possibility, therefore, is that slow changes in the state of the world oceans are necessary conditions for forcing the North Atlantic atmosphere on these longer time scales.

Evidence for this viewpoint comes from ensemble AGCM experiments where the model is forced with the known global evolution of SST and sea ice concentrations over the past 50 years $(10,11)$. One example of such a Global Ocean Global Atmosphere (GOGA) result is shown in the lower panel of Fig. 1 (12). It is clear that the low-frequency behavior in the simulated NAO time series, including an overall upward trend, closely resembles the observations. Indeed, the two filtered atmospheric time series (Fig. 1) are significantly correlated at 0.8 (13). This confirms the results of earlier GOGA ensemble experiments performed with different AGCMs and indicates that North Atlantic climate variability is not merely stochastic atmospheric noise, but rather contains a component that is a response to changes in ocean surface temperatures and/or sea ice $(10,11)$. But what portion of the world oceans is driving the North Atlantic atmosphere?

One working hypothesis has been that the North Atlantic basin itself is the most relevant $(10,14,15)$. A key and long-standing issue in this regard, however, has been the extent to which anomalous extratropical SST and upper ocean heat content anomalies feed back to affect the atmosphere. Most evidence suggests this effect is quite small on interannual time scales compared with internal atmospheric variability (16).

Another possibility is that changes in tropical heating force a remote atmospheric response over the North Atlantic that, in turn, drives changes in extratropical SSTs and sea ice. Simple linear regressions between global SSTs and the low-frequency observed and simulated NAO time series during boreal winter suggests the recent North Atlantic climate changes might originate from the tropics (Fig. 2). The regressions reveal a coherent pattern of tropic-wide warm SSTs associated with the positive NAO phase. In fact, the tropical loadings resemble the pattern of SST trend since 1950, the principal feature of which is a warming of Indo-Pacific waters (17).

To isolate the role of changes in tropical SSTs, another ensemble of simulations was performed. In these experiments, the time history of observed SSTs was specified over tropical latitudes $\left(30^{\circ} \mathrm{S}\right.$ to $\left.30^{\circ} \mathrm{N}\right)$ since 1950 , but the AGCM was forced by a repeating annual cycle of monthly climatological values of SST and sea ice at higher latitudes (18). These experiments are known as Tropical Ocean Global Atmosphere (TOGA) integrations. The observed wintertime trends in Northern Hemisphere $500 \mathrm{hPa}$ height are contrasted with those from the GOGA and TOGA simulations in Fig. 3.

It is evident that the observed NAO trend is part of a hemisphere-wide change in circulation that is also characterized by lower heights over the central North Pacific and higher heights over western Canada. The GOGA ensemble reproduces the spatial pattern of the trend remarkably well, but perhaps most striking is that 
much of the $500 \mathrm{hPa}$ height changes are recoverable from tropical SST forcing alone, thereby establishing that wintertime North Atlantic/European climate changes since 1950 are consistent with changes in tropical SSTs. It also follows that changes in extratropical SSTs are not generating a strong feedback in the GOGA integrations, and in fact a significant fraction of the NH extratropical SST changes appear to be a response to local changes in the wintertime atmospheric circulation that are tropically forced on long time scales. Similar arguments have been made for the role of tropical air-sea interactions in producing decadal climate variability over the North Pacific $(19,20)$, but Fig. 3 presents the strongest evidence to date that North Atlantic variability since 1950 also contains a tropically forced component.

It is well established that changes in tropical SSTs impact tropical rainfall and, thus, latent heating, which in turn drives changes in atmospheric circulation at higher latitudes. The best-known example is the anomaly in tropical eastern Pacific SSTs and rainfall associated with the El Niño-Southern Oscillation (ENSO) phenomenon, which produces climate anomalies across the globe on interannual time scales (21). The trend in rainfall derived from the TOGA runs (Fig. 4) reveals increased precipitation over the equatorial Indian Ocean that extends eastward toward the central Pacific, a response that is physically consistent with the warming trend of the underlying sea surface. This pattern has some features in common with the interannual ENSO signal in rainfall, but also has appreciable differences including the large zonal scale of enhanced rainfall and the strong response over the Indian Ocean. There are reasons to believe that these rainfall trends are realistic and are associated with an intensified hydrologic cycle (22), although limitations in observational data throughout the tropics do not permit a definitive verification (23).

Key questions concern the dynamical mechanisms by which changes in tropical rainfall and their associated heat sources and sinks influence the North Atlantic, and which changes in tropical rainfall are most relevant. Of particular interest is the appreciable drying over the equatorial Atlantic and South America, the amplitude of which is comparable to that of the increase in rainfall over the Indo-Pacific (Fig. 4). In other AGCM experiments, it has been suggested that variations in tropical and subtropical Atlantic SSTs affect convective activity over South America, which in turn produce a remote response over the North Atlantic $(14,15)$ akin to the atmospheric bridge mechanism operating over the Pacific during ENSO (24). There is also some observational evidence of a statistical link between the NAO and tropical and subtropical South Atlantic SSTs (25).

To explore the role of the tropical Atlantic in producing the observed, low-frequency North Atlantic climate variations (Fig. 1), a third ensemble of AGCM experiments was examined. In these simulations, observed SSTs since 1950 force the model over the tropical $\left(20^{\circ} \mathrm{S}\right.$ to $\left.20^{\circ} \mathrm{N}\right)$ Atlantic, but fixed climatological SSTs and sea ice are specified everywhere else (26). Simulated (five-member) ensemble mean rainfall changes of the same sign to those in the TOGA experiment occur over the equatorial Atlantic and South America (Fig. 4), but they are extremely weak (27). Moreover, the tropical Atlantic SST simulations exhibit no appreciable wintertime trend in $500 \mathrm{hPa}$ heights (27), and the simulated ensemble mean NAO time series has little correlation with the observed time series (Fig. 1). These results suggest that the tropical Atlantic heating anomalies evident in the TOGA experiment occur primarily in response to tropic-wide changes in circulation associated with warming surface waters over the Indo-Pacific region. It is also interesting to note that, although there is no theory that predicts how the North Atlantic circulation might respond to forcing from the Indo-Pacific region, a recent case study points to unprecedented interannual warming of these waters during 1998-2000 in forcing wintertime extratropical climate anomalies that bear
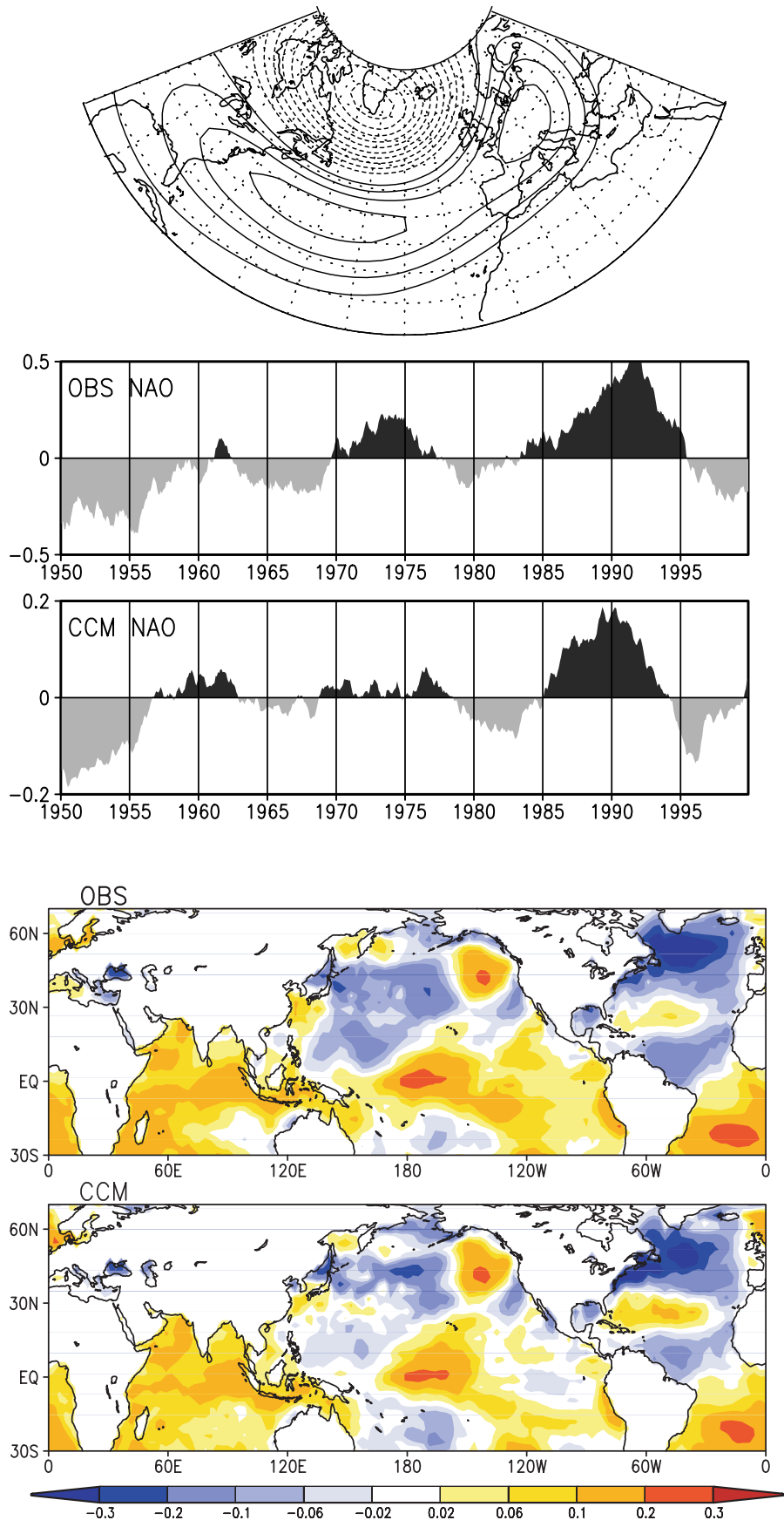

Fig. 1. The leading empirical orthogonal function (EOF) of observed North Atlantic $500 \mathrm{hPa}$ height (top) for the domain $100^{\circ} \mathrm{W}$ to $80^{\circ} \mathrm{E}, 20^{\circ} \mathrm{N}$ to $70^{\circ} \mathrm{N}$. The EOF explains $28 \%$ of the height variance over the region. The spatial pattern of the height EOF describes the North Atlantic Oscillation (NAO), and the height field reflects conditions during its "positive" phase. An identical analysis of the GCM yields a near-identical leading EOF (27). The monthly principal component time series of this EOF for 1950-1999, smoothed with a 73month running filter, for observations (middle) and the GOGA ensemble mean (bottom).

Fig. 2. The linear regression of winter season (December to February) SST onto the 73-month filtered observed (top) and filtered AGCM ensemble (bottom) NAO time series. Amplitudes are the change in SST per one standardized change in the filtered NAO time series. Warm SST amplitudes are linearly related to a positive NAO phase. 

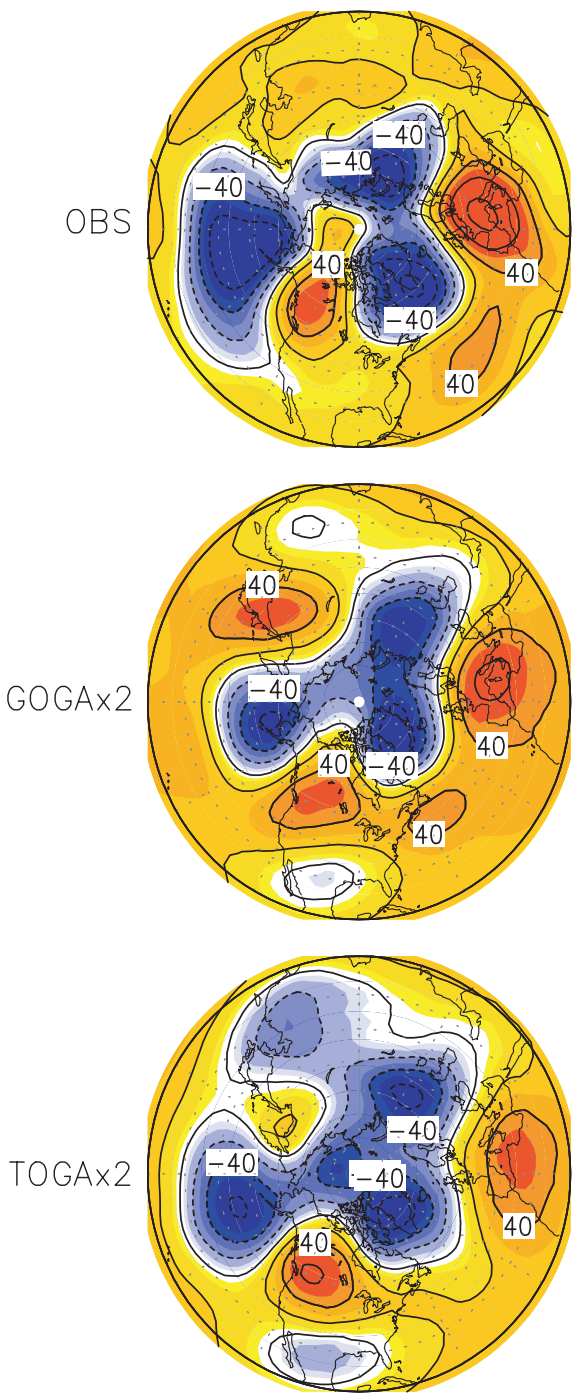

$-50-40-30-20-10-5 \quad 5 \quad 10 \quad 20 \quad 30 \quad 40 \quad 50$

Fig. 3. The linear trend of the winter season (December to February) $500 \mathrm{hPa}$ height field based on observations (top), the GOGA ensemble (middle), and the TOGA ensemble (bottom) over 1950-1999. The model results have been multiplied by a factor of 2 . Height increases (decreases) are indicated by solid (dashed) contours, and the contour increment is $20 \mathrm{~m}$ per 50 years.

considerable resemblance to those shown in Fig. 3 (28). We are currently working to more firmly establish the dynamics of these tropical teleconnections and their possible impact on North Atlantic climate variability. What is clear is that the most germane analysis must consider the role of the whole tropics in producing North Atlantic climate variability, not just the Atlantic sector.

We have argued, largely through atmospheric GCM experiments, that the observed wintertime trend in North Atlantic climate since 1950 is intimately linked with a gradual warming of tropical SSTs, in the sense that the latter is forcing the former. This leads to

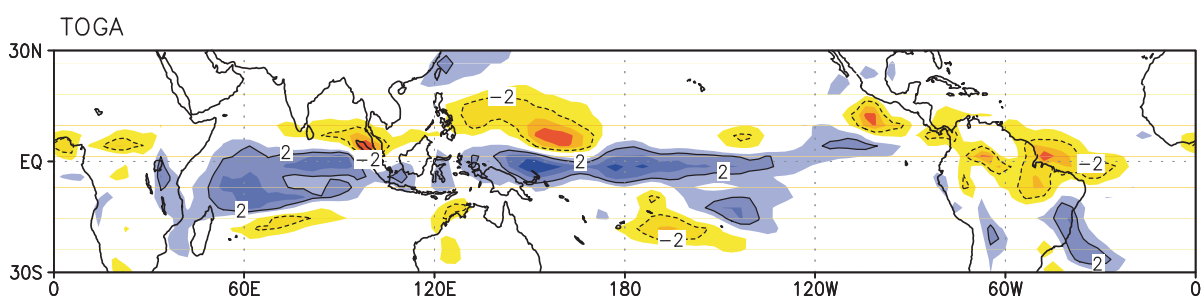

Fig. 4. The linear trend of the winter season (December to February) total precipitation (19501999) from the TOGA ensemble. Wet (dry) trends shown are shown in solid (dashed) contours, and the contour increment is $2 \mathrm{~mm}$ per 50 years.

the question of the origin of the tropical SST changes themselves. Although the possibility cannot be dismissed that the oceanic behavior is purely due to intrinsically coupled oceanatmosphere interactions, it is plausible that the oceans may also be responding to an external forcing. Solar forcing, for instance, appears to play a role in multi-century global surface temperature change since 1000 A.D. (29), but it appears to have little influence since 1950 (30). A more likely candidate over recent decades may be changes in the atmosphere's chemical composition due to human activities. Recent coupled ocean-atmosphere experiments, for instance, have shown at least part of the warming over the tropical oceans can be attributed to the influence of increased greenhouse gases $(17,31)$. Furthermore, such experiments also produce changes in tropical rainfall in response to anthropogenic SST warming that are similar to those in Fig. 4 (32). On the basis of our results, it is thus not unreasonable to claim that the North AtlanticEuropean climate change forced by the imposed slow warming of tropical SSTs constitutes an anthropogenic signal that has just begun to emerge during the last half-century.

\section{References and Notes}

1. J. W. Hurrell, Science 269, 676 (1995).

2. D. W. J. Thompson, J. M. Wallace, G. C. Hegerl, J. Clim. 13, 1018 (2000).

3. J. W. Hurrell, Geophys. Res. Lett. 23, 665 (1996).

4. J.-M. Fromentin, B. Planque, Mar. Ecol. Prog. Ser. 134, 111 (1996).

5. N. C. Stenseth et al., Science 285, 1071 (1999).

6. R. Saravanan, J. Clim. 11, 1386 (1998)

7. K. Yamazoki, Y. Shinya, J. Meteorol. Soc. Jpn. 77, 1287 (1999)

8. C. Wunsch, Bull. Amer. Meteorol. Soc. 80, 257 (1999).

9. T. J. Osborn, K. R. Briffa, S. F. B. Tett, P. D. Jones, R. M. Trigo, Clim. Dyn. 15, 1685 (1999).

10. M. J. Rodwell, D. P. Rowell, C. K. Folland, Nature 398, 320 (1999).

11. V. M. Mehta, M. J. Suarez, J. V. Manganello, T. L. Delworth, Geophys. Res. Lett. 27, 121 (2000).

12. The model data are from a 12-member ensemble of simulations performed with a recent version of the NCAR Community Climate Model, known as CCM3, over 1950-1999. The standard model configuration uses a triangular wave number 42 (T42) horizontal spectral resolution with 18 unequally spaced vertical (hybrid) levels. Observed, global monthly SSTs are assigned to the mid-month date and are updated every time step at each ocean grid point using linear interpolation. Ensemble experiments are analyzed to detect the climatic signal related to the imposed lower boundary forcing, in contrast to individual simulations that are dominated in the extratropics by chaotic, nonlinear atmospheric interactions (11). En- semble averaging reduces the amplitude of the simulated NAO time series to about one-half that of the observed. It is worthwhile to note that individual members of the ensemble have realistic amplitudes.

13. Linear correlations stated in the text as significant are so at the $5 \%$ level, taking into account the reduced degrees of freedom due to the 73-month running mean filter.

14. R. T. Sutton, W. A. Norton, S. P. Jewson, Atmos. Sci. Lett., in press.

15. A. W. Roberston, C. R. Mechoso, Y.-J. Kim, J. Clim. 13 122 (2000).

16. W. A. Robinson, Bull. Amer. Meteorol. Soc. 81, 567 (2000).

17. T. R. Knutson, T. L. Delworth, K. W. Dixon, R. J. Stouffer, J. Geophys. Res. 104, 30981 (1999).

18. A five-member ensemble of simulations was available at the time of analysis. Though smaller than the GOGA ensemble size, our analysis on the reproducibility of the low frequency variations in individual 50 -year realizations finds that the signal of SSTforced North Atlantic climate change since 1950 is strong and appears to be readily detectable in even a five-member ensemble average.

19. K. E. Trenberth, J. W. Hurrell, Clim. Dyn. 9, 303 (1994).

20. N. E. Graham, T. P. Barnett, R. Wilde, M. Ponater, S. Schubert, J. Clim. 7, 1416 (1995).

21. K. E. Trenberth et al., J. Geophys. Res. 103, 14291 (1998).

22. H. Flohn and A. Kapala, Nature 338, 244 (1989).

23. Ideally, observational data would allow us to confirm the realism of the AGCM rainfall responses, but the calculation of such trends in nature is hampered by insufficient data, both spatially and temporally over the 50-year span since 1950. Nonetheless, a recent data set (33) that estimates spatially complete observed rainfall (and other climate) variations since 1948 reveals a very similar trend pattern. This "reanalysis" data set, however, is based on an assimilation of atmospheric observations using a dynamical model, so it too can be sensitive to model physics. It is encouraging that the trend in simulated tropical rainfall (Fig. 4) is also similar to that occurring in the experiments of (11), performed with yet another AGCM. This argues that slow changes in tropical rainfall since 1950 are strongly constrained by changes in SST, and that they are not unduly sensitive to the representation of moist processes such as clouds and convection in the various models employed.

24. M. A. Alexander, J. Clim. 5, 944 (1992).

25. B. Rajagopalan, Y. Kushnir, Y. M. Tourre, Geophys. Res. Lett. 25, 3967 (1998).

26. R. Saravanan, P. Chang, J. Clim. 13, 2177 (2000)

27. M. P. Hoerling, J. W. Hurrell, T. Xu, data not shown.

28. M. P. Hoerling, A. Kumar, J. S. Whitaker, W. Wang, Geophys. Res. Lett. 28, 755 (2001).

29. T. J. Crowley, Science 289, 270 (2000).

30. S. F. B. Tett, P. A. Stott, M. R. Allen, W. J. Ingram, J. F. B. Mitchell, Nature 399, 569 (1999).

31. T. R. Knutson, S. Manabe, J. Clim. 11, 2273 (1998)

32. E. Roeckner et al., J. Clim. 12, 3004 (1999).

33. 24. E. M. Kalnay et al., Bull. Amer. Meteorol. Soc. 77, 437 (1996).

34. Supported by NOAA's Office of Global Program's CLIVAR/ATL program. The National Center for Atmospheric Research is sponsored by the National Science Foundation.

26 December 2000; accepted 5 March 2001 
This copy is for your personal, non-commercial use only.

If you wish to distribute this article to others, you can order high-quality copies for your colleagues, clients, or customers by clicking here.

Permission to republish or repurpose articles or portions of articles can be obtained by following the guidelines here.

The following resources related to this article are available online at www.sciencemag.org (this information is current as of February 17, 2016 ):

Updated information and services, including high-resolution figures, can be found in the online version of this article at:

/content/292/5514/90.full.html

A list of selected additional articles on the Science Web sites related to this article can be found at:

/content/292/5514/90.full.html\#related

This article cites 27 articles, 3 of which can be accessed free:

/content/292/5514/90.full.html\#ref-list-1

This article has been cited by 250 article(s) on the ISI Web of Science

This article has been cited by 23 articles hosted by HighWire Press; see:

/content/292/5514/90.full.html\#related-urls

This article appears in the following subject collections:

Atmospheric Science

/cgi/collection/atmos 